\title{
LC-ESI-IT-MS/MS and MALDI-TOF Approach: Identification of Natural Polymers from Rhizophora mangle Barks and Determination of Their Analgesic and Anti-inflammatory Properties
}

\author{
Leonardo Mendes de Souza Mesquita ${ }^{1}$ Caroline Fabri Bittencourt Rodrigues ${ }^{1}$ Cláudia Quintino da Rocha ${ }^{1,2}$. \\ Mayara Silveira Bianchim ${ }^{1} \cdot$ Clenilson Martins Rodrigues $^{3} \cdot$ Vanda Maria de Oliveira $^{3} \cdot$ Henrique Hessel Gaeta $^{1}$ • \\ Mariana Novo Belchor ${ }^{1} \cdot$ Marcos Hikari Toyama $^{1} \cdot$ Wagner Vilegas $^{1}$
}

Received: 20 August 2018 / Accepted: 31 October 2018/Published online: 14 November 2018

(C) The Author(s) 2018

\begin{abstract}
We recognize the chemical composition of the acetonic extract of Rhizophora mangle barks (AERM) using mass spectrometry analysis [liquid chromatography (LC)-ESI-IT-MS/MS and matrix-assisted laser desorption/ionization-time of flight-MS (MALDI-TOF)]. Analgesic activity was evaluated by formalin and tail-flick experimental assays. Anti-inflammatory activity was performed by paw edema test induced by carrageenan and 48/80 compounds. The first series of experiments involved [LC]-FIA-IT-MS/MS with 11 separated catechins derivatives until degree of polymerization 3 (DP3). The spectra obtained by MALDI-TOF analysis of the AERM presented two homologous series: one based on polymers of $\mathrm{m} / \mathrm{z} 288 \mathrm{Da}$ increments (up to DP12) and another series based on polymers of $\mathrm{m} / \mathrm{z}$ [288 +162 ] Da increments (up to DP11). In addition to these series of flavan-3-ol, each DP had a subset of masses with a variation of - 16 Da (homologous series of afzelechins $-m / z \quad 873-3465 \mathrm{Da}$ ) and $+16 \mathrm{Da}$ (homologous series of gallocatechins- $m /$ z 905-3497 Da). A similar pattern with homologous series of gallocatechins and afzelechins could also be observed for a fifth and a sixth monohexoside series: glucogallocatechins $(\mathrm{m} / \mathrm{z}$ 779-3371) and glucoafzelechins $(\mathrm{m} / \mathrm{z}$.747-3339). The intraperitoneal administration of different doses of AERM $\left(50,150\right.$ and $300 \mu \mathrm{g} \mathrm{mL}{ }^{-1}$ ) have a morphine-like effect and intense anti-inflammatory activity.
\end{abstract}

Wagner Vilegas

wagner.vilegas@unesp.br

1 Laboratory of Bioprospection of Natural Products (LBPN), UNESP - São Paulo State University/Coastal Campus of São Vicente, Pça Infante Dom Henrique S/N, São Vicente, São Paulo CEP: 11330-900, Brazil

2 Laboratório de Estudos Avançados em Fitomedicamentos (LEAF), UFMA - Federal University of Maranhão, Av. dos Portugueses, 1966 - Bacanga, São Luís, Maranhão CEP: 65080-805, Brazil

3 Embrapa Agroenergy, Brazilian Agricultural Research Corporation, W3 Norte, PqEB, Brasília, DF 70770-901, Brazil 


\section{Graphical Abstract}
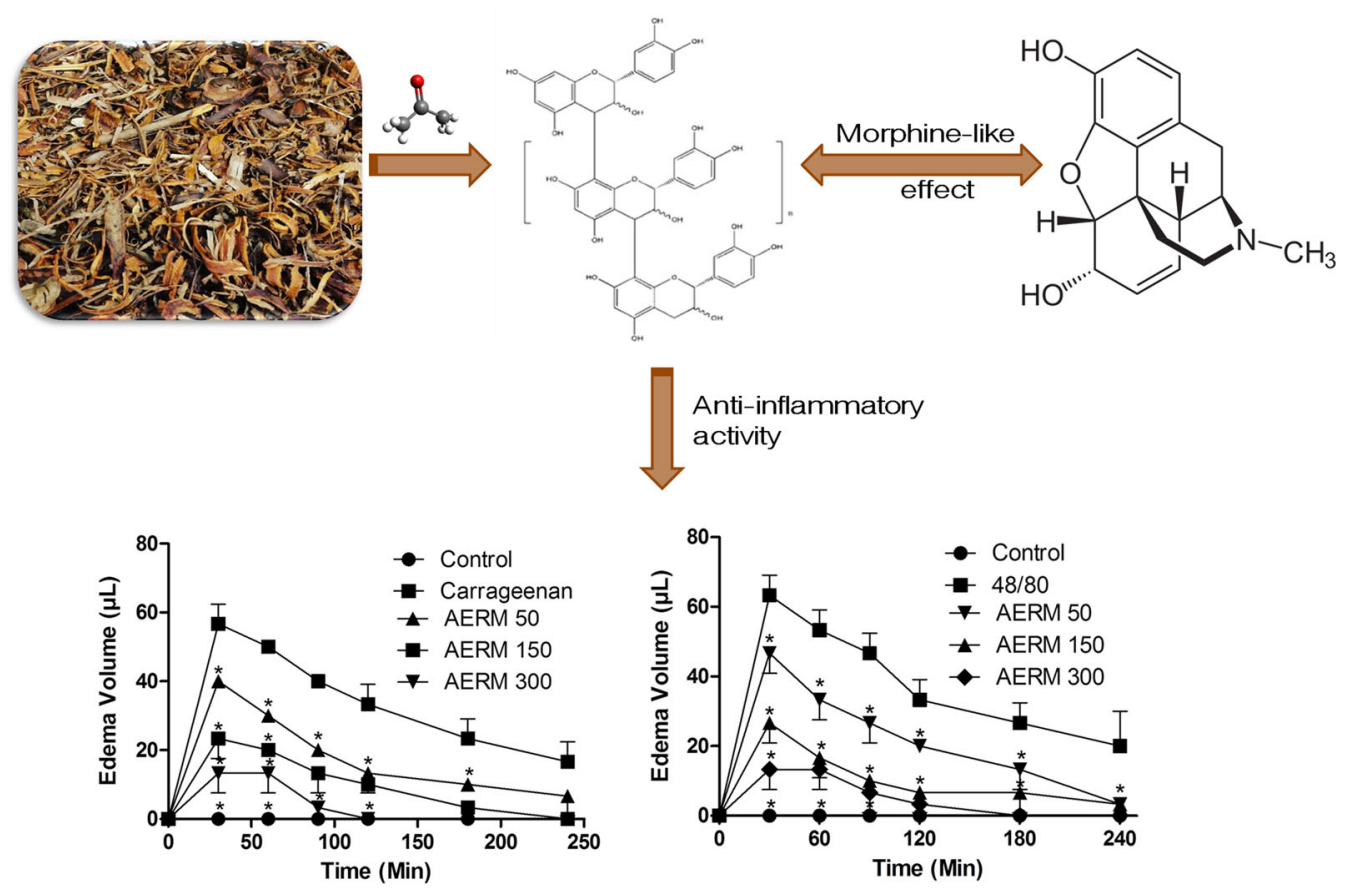

Keywords Catechins · Tannins · Morphine-like effect · Anti-inflammatory · Mangroves

\section{Introduction}

Rhizophora mangle L. (Rhizophoraceae) is a pioneer plant that dwelleth the estuarine ecosystem. Mangrove plants are potential sources of biologically active compounds with wide application in ethnopharmacology practices. These species dwell in stressful environmental conditions (salinity, tidal fluctuations, and anoxic soil), and are adapted to this harsh ecosystem having many substances that protect them from these conditions [1].

In traditional medicine, $R$. mangle is commonly used to treat diarrhea, ulcers, inflammation, tumors, diabetes, and pain $[1,2]$. Pain is the major reason for seeking medical consultations and represents high medical and economic costs to the community [3]. Opioids are the most used resource to treat this condition, but the continuous use of this compound can generate dependence and side effects, such as gastrointestinal problems and respiratory depression. Therefore, the search for new analgesics, especially those of natural origin, is a need and a challenge for medicinal chemistry [4].

Inflammatory diseases, despite being described many years ago, have no fully effective treatment, there are many side reactions caused by anti-inflammatory drugs. Therefore, a significant commercial interest to discover new anti- inflammatory drugs with fewer side effects has been observed nowadays [5]. Corticosteroids and nonsteroidal anti-inflammatories remain the major therapeutic resources for inflammation control [6], but these drugs induce significant side effects, especially when used for a prolonged period, as overload kidneys and liver, osteoporosis and anaphylactic shock [7].

The polyphenolic compounds such as proanthocyanidins (PAs-tannins) consisting of oligomers and polymers by flavan-3-ol units the are most abundant in Rhizophora [8]. Due to its variable degree of polymerization (DP), the isolation and identification of the PAs require the use of complex steps of separation and purification. Additionally, PAs are highly unstable compounds with complex molecular structures, thermolabile and photosensitive. Therefore, mass spectrometry (MS) techniques based on matrix-assisted laser desorption/ionization-time of flight-MS (MALDI-TOF-MS) and liquid chromatography coupled to the tandem MS (LC-MS) has been attracting attention because of their ability to reliable analysis. In this context, the purpose of the present study was to characterize the chemical composition of the acetone extract of $R$. mangle bark's (AERM) and evaluate the analgesic and anti-inflammatory activity, which can be an excellent alternative for the development of new drugs. 


\section{Results and Discussion}

Previous studies carried out with species of the genus Rhizophora and Rhizophoraceae family have demonstrated that these specimens are important sources of polyphenolic compounds (tannins) [2, 8]. MS experiments were performed using LC-MS system equipped with an ESI source and an Ion Trap analyser was made to investigate the presence of different compounds with the same molecular weight and then to perform a qualitative analysis on the PAs constituents occurring in the AERM.

In order to recognize the main class of compounds, we performed LC-ESI-MS/MS analysis. The chromatographic separation was optimized to obtain an excellent separation. The LC-ESI-MS/MS obtained has satisfactory chromatographic resolution (Fig. 1), with 11 separate compounds and their structure proposed in Table 1.

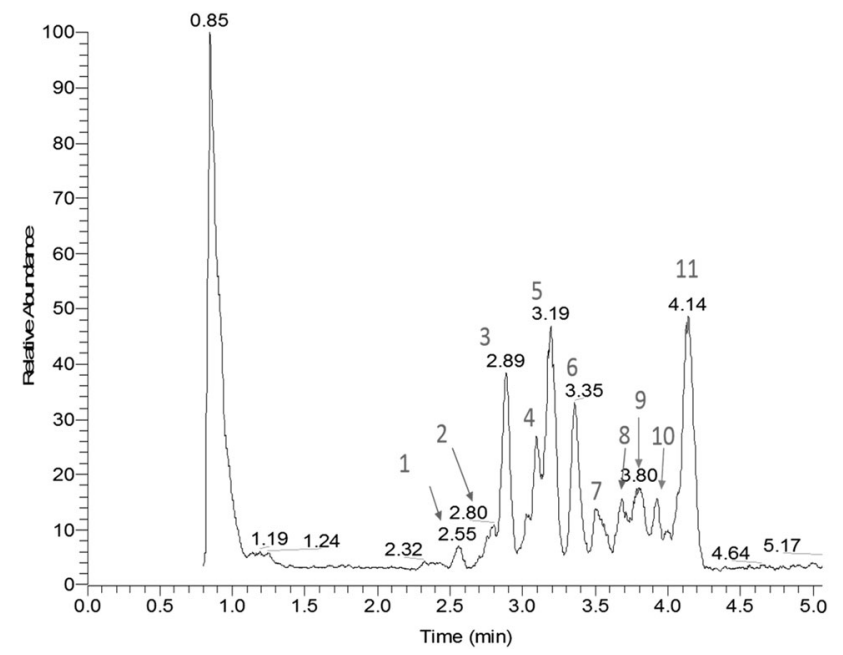

Fig. 1 Total ion chromatogram in negative ion UPLC-MS analysis of proanthocyanidins presents in the AERM
Compounds 1, 3, 7 and 8 were identified as catechin (CA) dimers based on their $[\mathrm{M}-\mathrm{H}]^{-}$precursor ion at $\mathrm{m} /$ $z$ 577, as well as after $\mathrm{MS}^{2}$ fragmentation, which resulted in the products ions at $\mathrm{m} / \mathrm{z} 425, \mathrm{~m} / \mathrm{z}, 407, \mathrm{~m} / \mathrm{z}, 272, \mathrm{~m} / \mathrm{z} 298$ and $\mathrm{m} / \mathrm{z} 228$, consistent with the data reported in the literature for CA dimmers [9]. Compound $2\left(m / z, 723,[\mathrm{M}-\mathrm{H}]^{-}\right)$was assigned as a CA dimer with one deoxyhexose moiety; $\mathrm{MS}^{2}$ fragmentation of this precursor ion led to the products ions at $\mathrm{m} / \mathrm{z}, 577, \mathrm{~m} / \mathrm{z} 571$ and $\mathrm{m} / \mathrm{z} 269$ [10]. Fragmentation of the precursor ion of $m / z 435[\mathrm{M}-\mathrm{H}]^{-}$(compound 4) led to the product ions at $m / z 289[\mathrm{M}-146-\mathrm{H}]^{-}$and $m / z$ 136, thus suggesting a $\mathrm{CA}$ core bounded to a deoxyhexose unit. Fragmentation of the compound $\mathbf{5}\left(\mathrm{m} / \mathrm{z} 739,[\mathrm{M}-\mathrm{H}]^{-}\right)$led to the fragments at $\mathrm{m} / \mathrm{z} 577[\mathrm{M}-162-\mathrm{H}]^{-}, \mathrm{m} / \mathrm{z} 559, \mathrm{~m} /$ $z 451, \mathrm{~m} / z 289$ and $\mathrm{m} / \mathrm{z} 269$ [10], corresponding to a CA core bounded to a hexose moiety. Compounds 6, 9, 10 and 11 were also identified as hexosyl-catechins, with $\mathrm{m} / \mathrm{z}, 451$ $[\mathrm{M}-\mathrm{H}]^{-}$and $\mathrm{MS}^{2}$ product ions at $\mathrm{m} / \mathrm{z}, 341[\mathrm{M}-162-\mathrm{H}]^{-}$.

There are two isomers of CAs: (+)-CA, and (-)-epicatechin (EC), they are considered geometric isomers, where CA in a trans form and EC in a cis form [11]. Their structure consists of two benzene rings ( $\mathrm{A}$ and $\mathrm{B}$ rings) connected through a pyran ring $\mathrm{C}$. The subtle difference in molecular structure may result in drastic differences in pharmacological processes and therapeutic efficacy [12]. Besides we cannot confirm the presence of these isomers by LC-MS/MS analysis, we suggest, that AERM possess these compounds. We detected for the compounds $\mathbf{1}, \mathbf{3}, \mathbf{7}, \mathbf{8}$ and compounds 6, 9, 10 and 11 different retention times and same $m / z$, thus strongly suggesting the presence of isomers.

CAs are classified as flavan-3-ol monomers and have the capacity to polymerize, forming oligomeric compounds with high molecular weight [13]. The polymeric character is evidenced by the chromatogram; however, the characterization of condensed tannins was limited with ESI-IT-
Table 1 LC-[MS/MS] fragmentations performed during the chromatographic analysis of the condensed tannins from AERM in the negative ionisation mode

\begin{tabular}{lllll}
\hline Peaks & $\operatorname{Tr}(\min )$ & {$[\mathrm{M}-\mathrm{H}]^{-}(\mathrm{m} / z)$} & $\mathrm{MS}^{\mathrm{n}}$ events & Proposed IDs \\
\hline $\mathbf{1}$ & 2.55 & 577 & $\mathrm{MS}^{2}: 425$ & Catechin dimer \\
& & & $\mathrm{MS}^{3}: 407,272,298,228$ & \\
$\mathbf{2}$ & 2.80 & 723 & $\mathrm{MS}^{2}: 571,577,269$ & Catechin dimer + deoxyhexose \\
$\mathbf{3}$ & 2.89 & 577 & $\mathrm{MS}^{2}: 425$ & Catechin dimer \\
$\mathbf{4}$ & 3.10 & 435 & $\mathrm{MS}^{2}: 289,136$ & Catechin + deoxyhexose \\
$\mathbf{5}$ & 3.19 & 739 & $\mathrm{MS}^{2}: 577$ & Catechin dimer + hexose \\
& & & $\mathrm{MS}^{3}: 559,451,289,269$ & \\
$\mathbf{6}$ & 3.35 & 451 & $\mathrm{MS}^{2}: 341,289$ & Catechin + hexose \\
$\mathbf{7}$ & 3.52 & 577 & $\mathrm{MS}^{2}: 425$ & Catechin dimer \\
$\mathbf{8}$ & 3.60 & 577 & $\mathrm{MS}^{2}: 425$ & Catechin dimer \\
$\mathbf{9}$ & 3.80 & 451 & $\mathrm{MS}^{2}: 341$ & Catechin + hexose \\
$\mathbf{1 0}$ & 3.95 & 451 & $\mathrm{MS}^{2}: 341$ & Catechin + hexose \\
$\mathbf{1 1}$ & 4.14 & 451 & $\mathrm{MS}^{2}: 341$ & Catechin + hexose
\end{tabular}



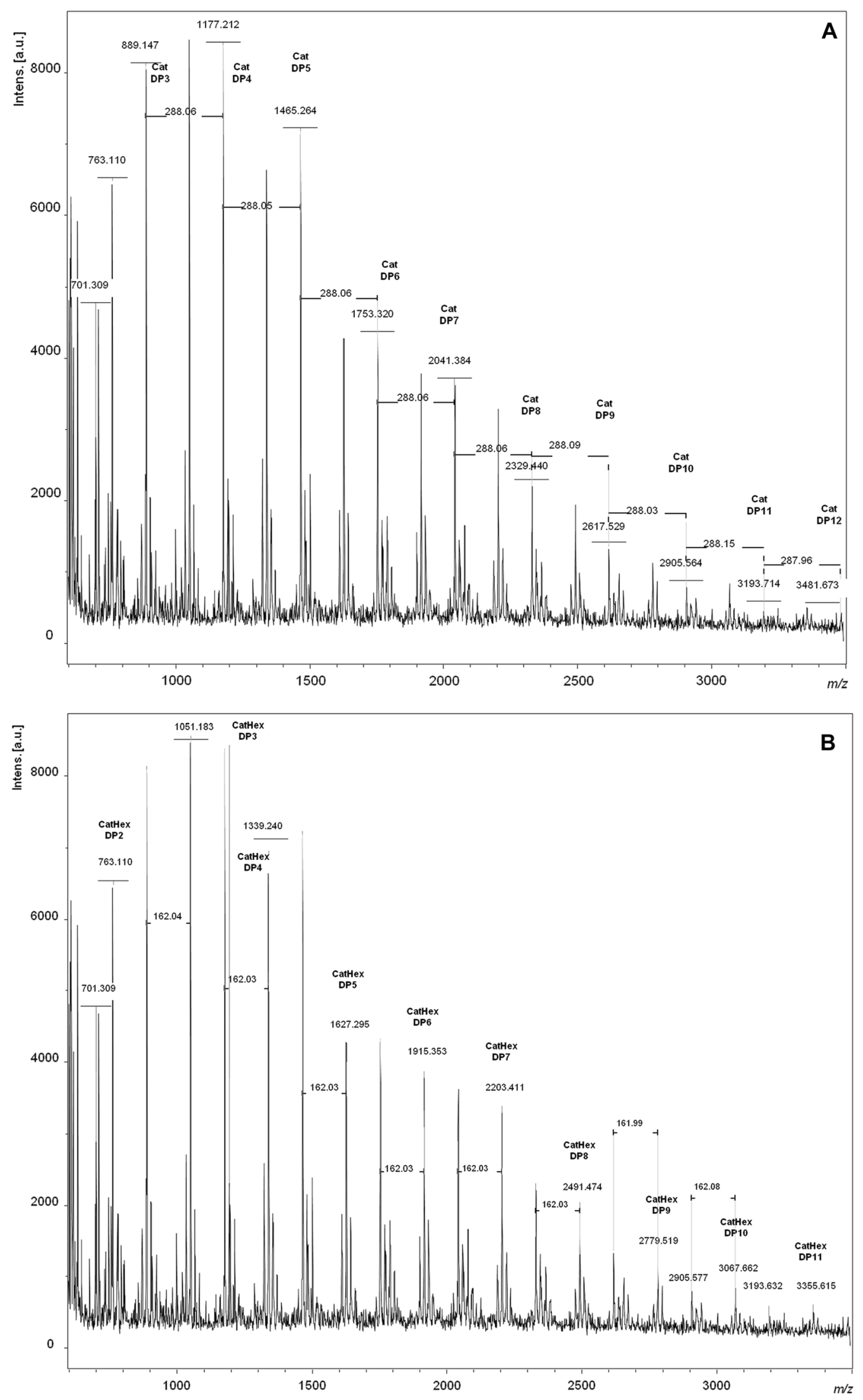

Fig. 2 MALDI-TOF positive reflectron mode mass spectra of the condensed tannins from $R$. mangle. A catechins series with varying hydroxylation patterns, B catechins series with hexose group and varying hydroxylation patterns 
Table 2 Summary of peaks with the highest intensities in MALDI-TOF MS of the condensed tannins from AERM

\begin{tabular}{|c|c|c|c|c|c|}
\hline Polymers & N1 catechins & N2 afzelechins & N3 gallocatechins & N4 hexoside & $\mathrm{MW}+\mathrm{Na}$ \\
\hline DP2 & 2 & 0 & 0 & 0 & 763.110 \\
\hline \multirow[t]{6}{*}{ DP3 } & 3 & 0 & 0 & 0 & 889.147 \\
\hline & 3 & 0 & 0 & 1 & 1051.18 \\
\hline & 2 & 1 & 0 & 0 & 747.133 \\
\hline & 2 & 0 & 1 & 0 & 905.145 \\
\hline & 1 & 2 & 0 & 0 & - \\
\hline & 1 & 0 & 2 & 0 & - \\
\hline \multirow[t]{12}{*}{ DP4 } & 4 & 0 & 0 & 0 & 1177.212 \\
\hline & 4 & 0 & 0 & 1 & 1339.240 \\
\hline & 4 & 1 & 0 & 0 & - \\
\hline & 3 & 0 & 1 & 0 & 905.145 \\
\hline & 3 & 1 & 0 & 1 & 1035.211 \\
\hline & 3 & 0 & 1 & 1 & 1067.178 \\
\hline & 2 & 2 & 0 & 0 & - \\
\hline & 2 & 0 & 2 & 0 & \\
\hline & 2 & 2 & 0 & 1 & \\
\hline & 2 & 0 & 2 & 1 & \\
\hline & 1 & 3 & 0 & 0 & \\
\hline & 1 & 0 & 3 & 0 & \\
\hline \multirow[t]{14}{*}{ DP5 } & 5 & 0 & 0 & 0 & 1465.264 \\
\hline & 5 & 0 & 0 & 1 & 1627.295 \\
\hline & 4 & 1 & 0 & 0 & - \\
\hline & 4 & 0 & 1 & 0 & 1193.210 \\
\hline & 4 & 1 & 0 & 1 & 1323.266 \\
\hline & 4 & 0 & 1 & 1 & 1355.230 \\
\hline & 3 & 2 & 0 & 0 & - \\
\hline & 3 & 0 & 2 & 0 & - \\
\hline & 3 & 2 & 0 & 1 & - \\
\hline & 3 & 0 & 2 & 1 & 1084.189 \\
\hline & 2 & 3 & 0 & 0 & - \\
\hline & 2 & 0 & 3 & 0 & - \\
\hline & 1 & 4 & 0 & 0 & - \\
\hline & 1 & 0 & 4 & 0 & - \\
\hline
\end{tabular}


Table 2 (continued)

\begin{tabular}{|c|c|c|c|c|c|}
\hline Polymers & N1 catechins & N2 afzelechins & N3 gallocatechins & N4 hexoside & $\mathrm{MW}+\mathrm{Na}$ \\
\hline \multirow[t]{16}{*}{ DP6 } & 6 & 0 & 0 & 0 & 1753.320 \\
\hline & 6 & 0 & 0 & 1 & 1915.353 \\
\hline & 5 & 1 & 0 & 0 & - \\
\hline & 5 & 0 & 1 & 0 & 1481.252 \\
\hline & 5 & 1 & 0 & 1 & 1611.313 \\
\hline & 5 & 0 & 1 & 1 & 1643.291 \\
\hline & 4 & 2 & 0 & 0 & - \\
\hline & 4 & 0 & 2 & 0 & - \\
\hline & 4 & 2 & 0 & 1 & - \\
\hline & 4 & 0 & 2 & 1 & 1372.240 \\
\hline & 3 & 3 & 0 & 0 & - \\
\hline & 3 & 0 & 3 & 0 & - \\
\hline & 2 & 4 & 0 & 0 & 1699.293 \\
\hline & 2 & 0 & 4 & 0 & - \\
\hline & 1 & 5 & 0 & 0 & - \\
\hline & 1 & 0 & 5 & 0 & - \\
\hline \multirow[t]{10}{*}{ DP7 } & 7 & 0 & 0 & 0 & 2041.384 \\
\hline & 7 & 0 & 0 & 1 & 1769.318 \\
\hline & 6 & 1 & 0 & 0 & 1738.328 \\
\hline & 6 & 0 & 1 & 0 & - \\
\hline & 5 & 2 & 0 & 0 & - \\
\hline & 5 & 0 & 2 & 0 & 2203.411 \\
\hline & 4 & 3 & 0 & 0 & - \\
\hline & 4 & 0 & 3 & 0 & - \\
\hline & 3 & 4 & 0 & 0 & - \\
\hline & 3 & 0 & 4 & 0 & - \\
\hline \multirow[t]{6}{*}{ DP8 } & 8 & 0 & 0 & 0 & 2329.440 \\
\hline & 8 & 0 & 0 & 1 & 2491.474 \\
\hline & 7 & 1 & 0 & 0 & 2025.402 \\
\hline & 7 & 0 & 1 & 0 & 2058.386 \\
\hline & 6 & 2 & 0 & 0 & - \\
\hline & 6 & 0 & 2 & 0 & - \\
\hline \multirow[t]{6}{*}{ DP9 } & 9 & 0 & 0 & 0 & 2617.529 \\
\hline & 9 & 0 & 0 & 1 & 2779.519 \\
\hline & 8 & 1 & 0 & 0 & - \\
\hline & 8 & 0 & 1 & 0 & 2345.434 \\
\hline & 8 & 1 & 0 & 1 & 2475.799 \\
\hline & 8 & 0 & 1 & 1 & 2507.576 \\
\hline \multirow[t]{6}{*}{ DP10 } & 10 & 0 & 0 & 0 & 2905.564 \\
\hline & 10 & 0 & 0 & 1 & 3067.662 \\
\hline & 9 & 1 & 0 & 0 & 2602.470 \\
\hline & 9 & 0 & 1 & 0 & - \\
\hline & 8 & 2 & 0 & 1 & - \\
\hline & 8 & 0 & 2 & 1 & 2523.489 \\
\hline
\end{tabular}


Table 2 (continued)

\begin{tabular}{llllll}
\hline Polymers & N1 catechins & N2 afzelechins & N3 gallocatechins & N4 hexoside & MW + Na \\
\hline DP11 & 11 & 0 & 0 & 0 & 1 \\
& 11 & 0 & 0 & 0 & 3193.713 \\
& 10 & 1 & 0 & 0 & - \\
& 10 & 0 & 1 & 0 & - \\
DP12 & 12 & 0 & 0 & 0 & - \\
& 12 & 0 & 0 & 0 & - \\
\hline
\end{tabular}

MS/MS experiments. To solve this bottleneck, analysis using MALDI-TOF MS was performed to establish the DP to the PAs and its glucosylated forms.

The spectra obtained by MALDI-TOF analyzes of the AERM presented two main homologous series: one with $288 \mathrm{Da}$ increments and another one with $288+162 \mathrm{Da}$ increments, corroborating with those found using LC-ESIIT-MS/MS technique. The series containing $288 \mathrm{Da}$ increments were attributed to the polymeric CAs, according to formula $290+288 \quad(\mathrm{n}-1)+23 \quad(\mathrm{n}=\mathrm{DP}$; + $23 \mathrm{Da}$ was attributed due to sodium adducts). Sodium adducts with up to DP12 (3481.673 Da) were found, even with the decrease in the intensity of the intercepted ions (Fig. 2a). In addition to this first series of flavan-3-ol, each DP had a subset of masses with a variation of -16 and $+16 \mathrm{Da}$ (Fig. 2a). These subsets can be explained by heteropolymers of repeating flavan-3-ol units containing an additional hydroxyl group $(\Delta+16 \mathrm{Da})$, characterizing a homologous series of gallocatechins $(\mathrm{m} /$ z 905.145-3497 Da) (Fig. 2a). The other series consists in heteropolymers of repeating flavan-3-ol units without a hydroxyl group $(\Delta-16 \mathrm{Da})$, that is, a homologous series of afzelechins ( $m / z$ 873-3465 Da) (Fig. 2a).

MALDI-TOF MS experiments indicated the occurrence of a mixture of PAs and its monohexoside derivatives, which presented a variable DP (from 2 up to 12). Each precursor ion of the condensed tannins from AERM was always followed by mass signals at $162 \mathrm{Da}$, suggesting the presence of a series of monohexoside anthocyanidins, that can be explained by the formula $290+288$ $(\mathrm{n}-1)+162+23$ (Fig. 2b). Condensed tannins with a hexose group with DP2-11 ( $\mathrm{m} / \mathrm{z}$ 763.110-3355.615) were detected in AERM (Fig. 2b). Species with up to DP11 CatHex $(\mathrm{m} / \mathrm{z}, 763.110-3355.615 \mathrm{Da})$ could be observed (Fig. 2b).

The same pattern with homologous series of gallocatechins and afzelechins could also be observed for monohexoside series, thus evidencing that the extract also possesses a series of monohexoside gallocatechins $(\mathrm{m} /$ $z$ 779-3371) as well as a series of monohexoside afzelechins $(\mathrm{m} / \mathrm{z}, 747-3339)$. The peaks with the highest intensities in MALDI-TOF MS of the AERM were summarized in Table 2.

Rhizophora species are traditionally used for the treatment of pain [14], but no scientific support corroborates this action, especially for $R$. mangle. There are already works evidencing the positive therapeutic effect of $R$. mangle in the treatment of gastro intestinal diseases [15], which cause a high sensation of pain [16]. Banerjee et al. reported a significant reduction in pain severity and frequency of painful episodes, in patients who underwent alternative treatment with extracts rich in grape PAs, reported a significant reduction in the use of narcotic analgesics. The mechanism of action by which tannins act in the pain treatment is still poorly explained, but it is a reality [17]. In order to evaluate the effect of AERM in the treatment of pain, we performed experimental tests with formalin and tail-flick assays.

Treatment of animals with AERM at doses of 50, 150 and $300 \mu \mathrm{g} \mathrm{kg}^{-1}$ did not induce any sign of intercurrence in the animals. This test showed that the doses do not interfere in an animal's behavior. The formalin test was performed to contribute to the tail-flick, whilst the former is better known to evaluate pain threshold or reflex through acute cutaneous stimulation, formalin injection induces a state that better approximates to clinical conditions, therefore evaluating tonic pain. Thus, in the first phase of the test, formalin predominantly evokes activity in $\mathrm{C}$ fibers, substance $\mathrm{P}$ and bradykinin, whilst histamine, serotonin, prostaglandins (PGs), and bradykinin are involved in the second phase [18]. Therefore, the formalin test allows the evaluation of analgesic effect in peripheral inflammatory processes, that is evoked especially in the second phase of the test. The stimulus provided by subcutaneous injection of formalin-induced a behavioral response in animals treated with formic acid, in contrast to animals treated with morphine and AERM compounds at different concentrations, which had almost no behavioral response to formalin injection in both phases of the formalin test. Therefore, the formalin test showed that there is no difference between the 


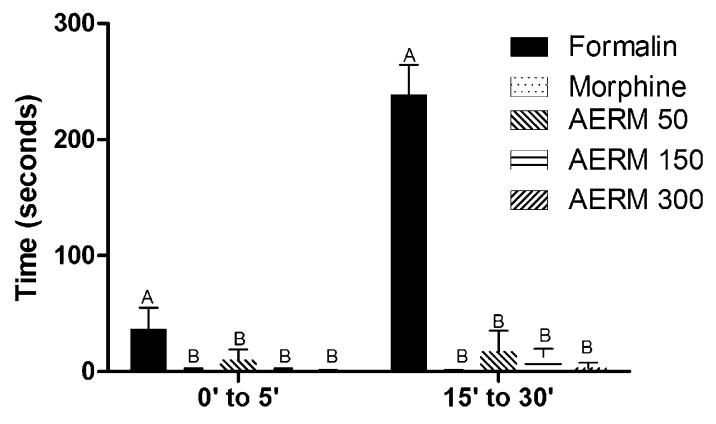

Fig. 3 Analgesic effect of AERM (50, 150 and $300 \mu \mathrm{g} \cdot \mathrm{kg}^{-1}$ ) on Formalin test. Results are expressed as mean \pm SEM $(n=6), p<$ 0.0001

analgesic effect of morphine and bark compounds in the lowest concentration tested, even in a test that provides a long-lasting pain stimulus such as the formalin test. Despite the dose-response tendency presented, there were no differences between the extract's concentrations tested in relation to the biological activity (Fig. 3; Table 3).

Tests with more phasic stimuli, such as the tail-flick tests, provide an evaluation of antinociceptive effect in acute pain state. In this scenario, the response to thermal stimuli was evaluated using the tail-flick test. As it was shown in Fig. 4 and Table 4, both the effect of morphine as well as the bark compounds in the lowest concentration, were substantially greater than in control (saline-treated animals). This result indicates that the AERM compounds had a spinal effect similar to morphine, though the exact mechanism is still unknown. The reason behind this morphine-like effect presented by the AERM may be due to the action of CAs, as it was shown previously that these substances act like blockers for sodium channels in neuronal cells [19]. Hence, this morphine-like effect observed for AERM has a significant clinical importance, as it could be used as a potential substitute for the morphine. Considering all the morphine's adverse effects (sedation, nausea, and pruritus) [15], the use of the AERM could improve the treatment of pain, especially chronically.

Pain may originate through an inflammatory process, several mediators such as cytokines, bradykinins and PGs are responsible for pain [20]. Our research group evidenced the anti-inflammatory activity of the ethyl acetate and butanol fractions of the AERM [21]. A scientific basis underpinned by the compounds of $R$. mangle may be

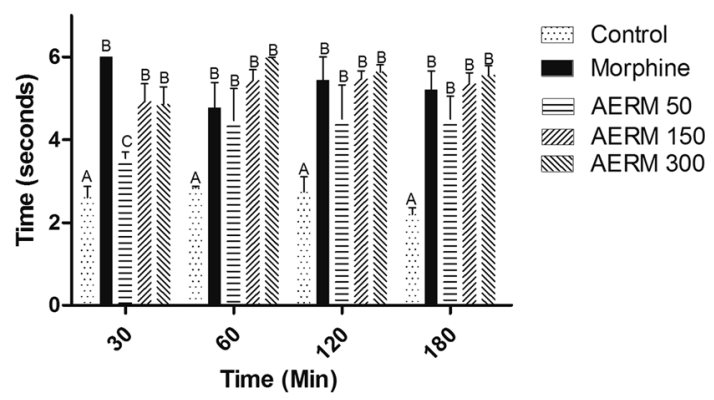

Fig. 4 Analgesic effect of AERM $\left(50,150\right.$ and $\left.300 \mu \mathrm{g} \cdot \mathrm{kg}^{-1}\right)$ on Tailflick test. Results are expressed as mean \pm SEM $(\mathrm{n}=6), p<0.0001$

helpful to explain its antinociceptive and anti-inflammatory effects. Pharmacological test of paw edema induced by carrageenan showed an anti-inflammatory potential, since there was the statistical difference (two-way analysis of variance, ANOVA with Bonferroni post test, $\mathrm{F}=61.46$, $p<0.01$, Df $=5$ ) (Fig. 5). Also, paw edema induced by compound $48 / 80$ also demonstrate a large inhibition when AERM was injected (two-way ANOVA with Bonferroni post test, $\mathrm{F}=43.00, p<0.01, \mathrm{Df}=5$ ) (Fig. 6).

The acute inflammatory response is characterized by an increase in vascular permeability and cellular infiltration leading to edema formation, because of extravasation fluid and proteins and accumulation of leukocytes at the inflammatory site [22]. Carrageenan-induced paw edema is a widely-used test to determine the anti-inflammatory activity and induced cyclo-oxygenase-2 (COX-2) maximal expression $1 \mathrm{~h}$ from carrageenan local injection. However, compound 48/80, like other basic secretagogues, causes mast cell degranulation via direct activation of Gi proteins (sensitive to Pertussis toxin), releasing oxygen reactive species (ROS). Degranulation of mast cells results in the release of stored autacoids, such as histamine, as well as the de novo synthesis of arachidonic acid (AA), cytokines and chemokines. Upon mast cell degranulation, AA is released and metabolized through COX or 5-lipoxygenase (5-LO) pathways to yield, respectively, PGs and thromboxane, or leukotrienes [23, 24]. So, phenolic compounds as found in $R$. mangle could be actin by controlling the mast degranulation as ROS scavenger and might inhibit specifically enzymes from the inflammatory process as COX-2 [25].
Table 3 Analgesic effect by formalin test of AERM $(50,150$ and $300 \mu \mathrm{g} \mathrm{kg}^{-1}$ )

\begin{tabular}{llllll}
\hline Time $(\min )$ & Formalin & Morphine & AERM 50 & AERM 150 & AERM 300 \\
\hline $0^{\prime}-5^{\prime}$ & $36.54 \pm 18.52^{\mathrm{A}}$ & $1.08 \pm 1.52^{\mathrm{B}}$ & $10.10 \pm 8.95^{\mathrm{B}}$ & $1.05 \pm 1.47^{\mathrm{B}}$ & $0.50 \pm 0.99^{\mathrm{B}}$ \\
$15^{\prime}-30^{\prime}$ & $238.80 \pm 25.61^{\mathrm{A}}$ & $0.51 \pm 0.95^{\mathrm{B}}$ & $17.03 \pm 18.42^{\mathrm{B}}$ & $12.77 \pm 6.77^{\mathrm{B}}$ & $3.23 \pm 4.46^{\mathrm{B}}$
\end{tabular}

Significant difference was marked with different letters in the same row (two-way ANOVA, mean and standard deviation, Bonferroni post hoc test, $\mathrm{p}<0.01, \mathrm{~F}=229.7$ ) 
Table 4 Analgesic effect by tail-flick test of AERM $(50,150$ and $300 \mu \mathrm{g} \mathrm{kg}^{-1}$ )

\begin{tabular}{llllll}
\hline Time (min) & Control & Morphine & AERM 50 & AERM 150 & AERM 300 \\
\hline 30 & $2.60 \pm 0.46^{\mathrm{A}}$ & $6.00 \pm 0.00^{\mathrm{B}}$ & $3.55 \pm 0.21^{\mathrm{C}}$ & $4.91 \pm 0.88^{\mathrm{B}}$ & $4.85 \pm 0.96^{\mathrm{B}}$ \\
60 & $2.83 \pm 0.058^{\mathrm{A}}$ & $4.77 \pm 1.07^{\mathrm{B}}$ & $4.47 \pm 1.33^{\mathrm{B}}$ & $5.42 \pm 0.60^{\mathrm{B}}$ & $5.97 \pm 0.04^{\mathrm{B}}$ \\
120 & $2.73 \pm 0.63^{\mathrm{A}}$ & $5.43 \pm 0.98^{\mathrm{B}}$ & $4.50 \pm 1.41^{\mathrm{B}}$ & $5.46 \pm 0.40^{\mathrm{B}}$ & $5.63 \pm 0.43^{\mathrm{B}}$ \\
180 & $2.20 \pm 0.26^{\mathrm{A}}$ & $5.20 \pm 0.80^{\mathrm{B}}$ & $4.50 \pm 0.95^{\mathrm{B}}$ & $5.35 \pm 0.60^{\mathrm{B}}$ & $5.55 \pm 0.58^{\mathrm{B}}$ \\
\hline
\end{tabular}

Significant difference was marked with different letters in the same row (two-way ANOVA, mean and standard deviation, Bonferroni post hoc test, $\mathrm{p}<0.01, \mathrm{~F}=46.27$ )

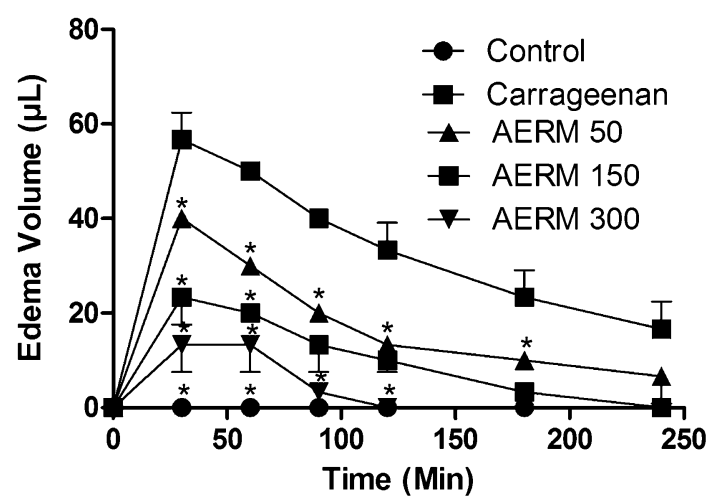

Fig. 5 Monitoration of paw edema induced by carrageenan. The analysis showed an inhibition when treatments were injected with AERM. Two-way ANOVA with Bonferroni as a post test $(p<0.01)$. Statistical differences relative to carrageenan (filled squares) are marked with *

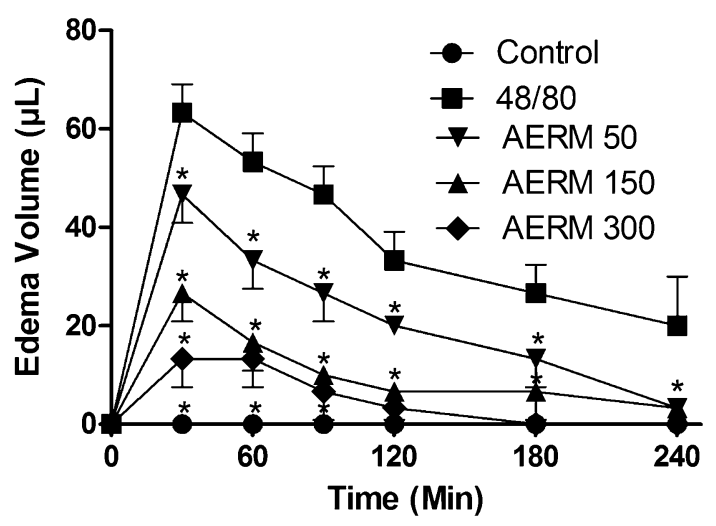

Fig. 6 Monitoration of paw edema induced by 48/80. The analysis showed an inhibition when treatments were injected with AERM. Two-way ANOVA with Bonferroni as a post test $(p<0.001)$. Statistical differences relative to the compound $48 / 80$ (filled squares) are marked with *

Furthermore, Pinus pinaster is also rich in polyphenolic compounds, such as afzelechins and galocatechins, same as found in $R$. mangle, and has been shown to have similar analgesic and anti-inflammatory effects as $R$. mangle [26]. Pinus pinaster cause inhibition of cyclo-oxygenase (COX1 and COX-2) activity in serum samples of human volunteers. COXs enzymes are the major targets for the treatment of inflammation, fever and pain, due to its function, that is synthesis of mediators, such as PGs, prostacyclin, and thromboxane. Which suggests, that the COX blockage may also play a role in the analgesic and anti-inflammatory effect of $R$. mangle due to polyphenolic compounds activity.

Several anti-inflammatory drugs on market are known, however, they reveal side effects such as liver and kidney commitment [27]. Other species by genus Rhizophora have anti-inflammatory activity [28]. In $R$. mangle, inhibition of PLA2 and COX-2, enzymes related to inflammation process, demonstrated by in vitro tests [14], which reiterates the results revealed in this study. Kanagaratnam et al. [29] reported that CAs may act as an anti-inflammatory because they reveal antibacterial activity; which probably supports the results found in this work. Another mechanism capable of generating pain can originate in response to tissue damage or physiological stress, including oxidative stress [30]. The condensed tannins present in $R$. mangle have excellent free radical sequestration [21], thus, the antioxidant capacity of this extract can aid in the maintenance of pain and inflammation.

\section{Conclusions}

This research showed the potential of UPLC coupled to ion trap tandem MS and MALDI-TOF analysis for the rapid and sensitive detection of natural phenolic polymers in the acetone extract from the barks of $R$. mangle. This technique allowed detecting the presence of a series of anthocyanidins in less than 5 min of analysis. MALDI-TOF MS allowed characterizing all the polymeric substances present in the extract, revealing the presence of a series of condensed tannins based on CAs, gallocatechins and afzelechins. Besides, these series were accompanied by their respective glucosilated derivatives. The identification of these compounds has provided relevant data for fully characterize the secondary metabolites present in these complex vegetal extracts. The chemical characterization of the extract also helped to understand the results observed in the formalin, tail-flick and paw edema assays using experimental models, which demonstrated the antinociceptive and anti-inflammatory effects of the AERM. 


\section{Experimental Section}

\subsection{Plant Material}

The barks of $R$. mangle L. (Rhizophoraceae) were collected during August 2015 from the estuary of the ecological station of Juréia-Itatins (Peruíbe, São Paulo, Brazil, $\left.24^{\circ} 25^{\prime} 40^{\prime \prime} \mathrm{S}-47^{\circ} 05^{\prime} 20^{\prime \prime} \mathrm{W}\right)$. The collecting the material had prior authorization from the Brazilian authorities (IBAMA/ MMA: 52497-1). The taxonomic identification of the plant was carried out by Prof. Paulo Sampaio. The voucher specimens $\left(n^{\circ} 11459\right)$ has been deposited at the Herbarium HUSC of the Santa Cecilia University (Santos, São Paulo, Brazil).

\subsection{Preparation of Plant Extract (AERM)}

Fresh barks of $R$. mangle were washed, shade dried, powdered in a knife mill and sieved through a \#60 mesh sieve. The powder $(50 \mathrm{~g})$ was extracted with $0.5 \mathrm{~L}$ acetone:water $(70 \% \mathrm{v} / \mathrm{v})$ and macerated for 7 days at room temperature $\left(24^{\circ} \mathrm{C}\right)$, protected from light. The macerate was filtered through Whatman No. 1 filter paper and concentrated in a rotating flash evaporator at a temperature not exceeding $35^{\circ} \mathrm{C}$. The extract was lyophilized and stored in amber glass flasks, stored in a freezer $\left(-40{ }^{\circ} \mathrm{C}\right)$ and resuspended with distilled water for use in pharmacological experiments. The percent yield of the lyophilized powder was $7 \%$ of the dry plant material.

\subsection{Phytochemical Evaluation}

\subsubsection{LC-ESI-MS/MS Analysis}

MS analyses were carried out in a Thermo Finnigan (San Jose, CA, USA) LCQ mass spectrometer equipped with an electro-spray ionization source, ion-trap analyzer and Xcalibur software for data processing. For LC-MS analysis: column Phenomenex, $300 \mu \mathrm{L} \mathrm{min}{ }^{-1}$, followed by chromatographic using $\mathrm{MeOH}$ and $0.002 \%$ formic acid in water was added using a linear gradient from 0 to $100 \%$ $\mathrm{MeOH}$ over $5 \mathrm{~min}$. The mass spectrometer was operated in the negative ion mode under the following conditions: flow $5 \mu \mathrm{L} \mathrm{min}{ }^{-1}$; the capillary temperature $270{ }^{\circ} \mathrm{C} ; 80$ arbitrary units of nitrogen; gas assist with 5 arbitrary units. All solvents used in these analyzes have a mass grade, purchased from Sigma.

\subsubsection{MALDI-TOF}

For the analysis using MALDI-TOF, $1.0 \mathrm{mg}$ of the powdered vegetable material was diluted in $500 \mu \mathrm{L}$ of $\mathrm{MeOH}$ containing 2,5-dihydroxybenzoic acid (DHB - $125 \mathrm{~nm}$ ) and sodium iodide $(1 \mathrm{nM})$ with the addition of $1 \%$ trifluoroacetic acid (v/v), purchased from Sigma. This solution was placed for $1 \mathrm{~min}$ by vortexing. After this, $1 \mu \mathrm{L}$ of the solution suspension has been deposited on MALDI plates, made of stainless steel and allocated to air dry prior to analysis. The analysis of MALDI-MS was carried out a Voyager DE-RP coupled to the spectrometer flight time mass (TOF), equipped with a nitrogen laser $(\lambda=337 \mathrm{~nm}$, pulse width $3 \mathrm{rd})$. The intensity of the laser beam was experimentally attenuated slightly above the threshold level for forming ions from the tannin components. The ions generated by laser desorption were introduced in the flight tube with a $20 \mathrm{kV}$ accelerating voltage in positive linear mode. The delay time is $100 \mathrm{~ns}$. All mass spectra were acquired by averaging 100 individual laser shots [31].

\subsection{Experimental Analysis}

\subsubsection{Animals}

Ethical approval for the animal studies was obtained from the Animal Use Committee of the São Paulo State University, reference number: 019 CEUA/CLP, UNESP, São Paulo State University/Coastal Campus of São Vicente, on August 2016. The experiments were performed with a minimum number of animals that provides a robust analysis. Healthy adult female Wistar rats weighing 25-30 $\mathrm{g}$ at $8-12$ weeks $(\mathrm{n}=6)$ The experiments were performed in independent duplicates and were obtained from Campinas University (Campinas, São Paulo, Brazil). The animals were kept in standard environmental conditions: temperature $\left(23 \pm 2{ }^{\circ} \mathrm{C}\right)$, light control $(12 \mathrm{~h}$ light cycle) and provide water and food ad libitum (standard rodent diet), except during the experimental period. All animals were acclimated for a period of 5 days before the start of the experimental assays.

\subsubsection{Formalin Assay}

Formalin test was done according to the modified method of [32]. Each animal was placed inside a box $(30 \times 30 \times 30 \mathrm{~cm}$, length $\times$ width $\times$ height $)$ after formalin injection in right foot plantar area $(1 \% \mathrm{v} / \mathrm{v})$. Thus, Swiss female mice fasted for a period of $8 \mathrm{~h}$ and divide$\mathrm{d}$ into five groups $(\mathrm{n}=6)$, Control $(\mathrm{NaCl} 0.9 \%)$, Morphine $\left(50 \mu \mathrm{g} \mathrm{kg}^{-1}\right.$, i.p.) and AERM treated with $R$. mangle extracts $\left(50,150\right.$ and $\left.300 \mu \mathrm{g} \mathrm{kg}^{-1}\right)$. After $1 \mathrm{~h}$ of each treatment, animals were given an intraplantar formalin injection $(20 \mu \mathrm{L} ; 2 \%)$. Two responses were analyzed: acute-phase (0-5 min) and later-phase (15-30 min) $[33,34]$, it is considered the zero time point when formalin was immediately injected. 


\subsubsection{Tail-Flick Assay}

Tail-flick test was evaluated of central analgesic activity [35]. The latency period is used as a determination index of nociception. Data collected from mice with latency lower than $2 \mathrm{~s}$ were not used, and $6 \mathrm{~s}$ was the maximum latency tolerance. Animals were divided into five groups $(n=6)$, Control (saline solution), Morphine $\left(50 \mu \mathrm{g} \mathrm{kg}^{-1}\right.$, i.p.) and $\operatorname{AERM}\left(50,150\right.$ and $300 \mu \mathrm{g} \mathrm{kg}^{-1}$, i.p.), an analgesymeter (Insight EFF 300L), with the tail docked in apparatus with the light thermal source was used. The latency of tail withdrawal response was determined $0,30,60,120$ e $180 \mathrm{~min}$ after the AERM administration, inject peritoneally.

\subsubsection{Paw Edema Test Induced by Carrageenan and $48 / 80$ Compounds}

AERM was injected peritoneally $(50,150$ and $\left.300 \mu \mathrm{g} \mathrm{mL}^{-1}\right), 10 \mathrm{~min}$ after carrageenan $(1.5 \%)(\mathrm{n}=6)$, and $48 / 80(2 \%)(\mathrm{n}=6)$ in Swiss mice. For controls, we used saline $(\mathrm{NaCl} 0.9 \%)$. The monitoring of edema volume was using plethysmometer for $4 \mathrm{~h}$ or until diminution of inflammation reaches $20 \%$ of the original.

\subsection{Statistical Analysis}

All data were expressed as a mean \pm standard error of the mean. Statistical analyses were performed by using the Statistical Package for Social Science version 15.0 (SPSS) and GraphPad Prism 5.0. The statistical significance was determined using a two-way ANOVA, followed by Bonferroni post hoc test, a level of $5 \%(p<0.05)$ was considered to be statistically significant.

Acknowledgements This work was supported by Fundação de Amparo à Pesquisa do Estado de São Paulo (FAPESP) (Grant 2009/52237-9 to WV, fellowship 2014/23951-3 to LMSM). The authors also thank Paulo Sampaio, from the Herbarium HUSC of the Santa Cecilia University, Brazil for assistance with botanical identification.

Author Contributions Authors W.V., C.Q.R., C.M.R., M.H.T. conceived the study. L.M.d.S.M., C.F.B.R., M.S.B., V.M.O., M.N.B., H.H.G. collected the plant material and prepared the extracts. All the authors performed the experiments, the analysis of data and the drafting of the manuscript. All authors read, revised and approved the final manuscript.

\section{Compliance with Ethical Standards}

Conflict of interest The authors declare no conflict of interest.

Open Access This article is distributed under the terms of the Creative Commons Attribution 4.0 International License (http://creative commons.org/licenses/by/4.0/), which permits unrestricted use, distribution, and reproduction in any medium, provided you give appropriate credit to the original author(s) and the source, provide a link to the Creative Commons license, and indicate if changes were made.

\section{References}

1. M. Nebula, H. Harisankar, N. Chandramohanakumar, Nat. Prod. Bioprospect. 3, 207 (2013)

2. F. Kandil, M. Grace, D. Seigler, J. Cheeseman, Trees 18, 518 (2004)

3. C.B. Groenewald, B.S. Essner, D. Wright, M.D. Fesinmeyer, T.M. Palermo, J. Pain 15, 925 (2014)

4. S.R. Savage, K.L. Kirsh, S.D. Passik, Addict. Sci. Clin. Pract. 4, 4 (2008)

5. A.G. Atanasov, B. Waltenberger, E.-M. Pferschy-Wenzig, T. Linder, C. Wawrosch, P. Uhrin, V. Temml, L. Wang, S. Schwaiger, E.H. Heiss, Biotechnol. Adv. 33, 1582 (2015)

6. E.R. Rayburn, S.J. Ezell, R. Zhang, Mol. Cell. Pharmacol. 1, 29 (2009)

7. S. Shaikh, H. Verma, N. Yadav, M. Jauhari, J. Bullangowda, ISRN Anesthesiol. (2012). https://doi.org/10.5402/2012/985495

8. L.-L. Zhang, Y.-M. Lin, H.-C. Zhou, S.-D. Wei, J.-H. Chen, Molecules 15, 420 (2010)

9. F.M. de-Faria, A.C.A. Almeida, A. Luiz-Ferreira, C. Takayama, R.J. Dunder, M.A. da Silva, M.J. Salvador, P.V. Abdelnur, M.N. Eberlin, W. Vilegas, Sci. World J. (2012). https://doi.org/10. 1100/2012/327071

10. M. Maldini, P. Montoro, S. Piacente, C. Pizza, Nat. Prod. Commun. 4, 1671 (2009)

11. C. Yan, Z. Xiu, X. Li, C. Hao, J. Mol. Graph. Model. 26, 420 (2007)

12. M. Liu, Y. Zheng, C. Wang, J. Xie, B. Wang, Z. Wang, J. Han, D. Sun, M. Niu, Food Chem. 196, 148 (2016)

13. H.-J. Li, M.L. Deinzer, Anal. Chem. 79, 1739 (2007)

14. E. de Armas, Y. Sarracent, E. Marrero, O. Fernández, C. Branford-White, Curr. Med. Res. Opin. 21, 1711 (2005)

15. P. Glare, D. Walsh, D. Sheehan, Am. J. Hosp. Palliat. Med. 23, 229 (2006)

16. B. Banerjee, D. Bagchi, Digestion 63, 203 (2001)

17. Z. Zakaria, E. Jaios, M. Omar, S.A. Rahman, S. Hamid, S. Ching, L. Teh, M. Salleh, S. Deny, M. Taher, BMC Complement. Altern. Med. 16, 488 (2016)

18. A. Tjølsen, O.-G. Berge, S. Hunskaar, J.H. Rosland, K. Hole, Pain 51, 5 (1992)

19. L. da Silva Lopes, R.B. Marques, H.B. Fernandes, S. da Silva Pereira, M.C. Ayres, M.H. Chaves, F.R. Almeida, J. Biomed. Sci. 19, 68 (2012)

20. E. Ricciotti, G.A. FitzGerald, Arterioscler. Thromb. Vasc. Biol. 31, 986 (2011)

21. F.M. de Faria, A. Luiz-Ferreira, E.A.R. Socca, A.C.A. de Almeida, R.J. Dunder, L.P. Manzo, M.A. da Silva, W. Vilegas, A.L. Rozza, C.H. Pellizzon, Evid. Based Complement. Altern. Med. (2012). https://doi.org/10.1155/2012/753971.753971

22. I. Posadas, M. Bucci, F. Roviezzo, A. Rossi, L. Parente, L. Sautebin, G. Cirino, Br. J. Pharmacol. 142, 331 (2004)

23. B. Damerau, L. Lege, H.-D. Oldigs, W. Vogt, Naunyn Schmiedebergs Arch. Pharmacol. 287, 141 (1975)

24. H. Karmouty-Quintana, F. Blé, C. Cannet, S. Zurbruegg, J.R. Fozard, C. Page, N. Beckmann, Br. J. Pharmacol. 154, 1063 (2008)

25. A. Amić, Z. Marković, J.M.D. Marković, S. Jeremić, B. Lučić, D. Amić, Comput. Biol. Chem. 65, 45 (2016) 
26. A. Schäfer, Z. Chovanová, J. Muchová, K. Sumegová, A. Liptáková, Z. Duračková, P. Högger, Biomed. Pharmacother. 60, 5 (2006)

27. S. Melgaço, M. Saraiva, T. Lima, G. Junior, E. Daher, Medicina (Mex.) 43, 382-390 (2010)

28. R. Rohini, A. Das, Pharm. Lett. 2, 95 (2010)

29. R. Kanagaratnam, R. Sheikh, F. Alharbi, D.H. Kwon, Phytomedicine 36, 194 (2017)

30. A.I. Basbaum, D.M. Bautista, G. Scherrer, D. Julius, Cell 139, 267 (2009)
31. Y. Ishida, K. Kitagawa, K. Goto, H. Ohtani, Rapid Commun. Mass Spectrom. 19, 706 (2005)

32. D. Dubuisson, S.G. Dennis, Pain 4, 161 (1977)

33. S. Hunskaar, K. Hole, Pain 30, 103 (1987)

34. M. Shibata, T. Ohkubo, H. Takahashi, R. Inoki, Pain 38, 347 (1989)

35. D. Le Bars, M. Gozariu, S.W. Cadden, Pharmacol. Rev. 53, 597 (2001) 